\title{
Single-dose fosaprepitant for the prevention of chemotherapy-induced nausea and vomiting in patients receiving moderately emetogenic chemotherapy regimens: a subgroup analysis from a randomized clinical trial of response in subjects by cancer type
}

Cindy Weinstein ${ }^{1 *}$, Karin Jordan², Stuart Green ${ }^{1}$, Saleem Khanani ${ }^{3}$, Elizabeth Beckford-Brathwaite ${ }^{1}$, Waldimir Vallejos', Annpey Pong ${ }^{1}$, Stephen J. Noga ${ }^{4}$ and Bernardo L. Rapoport ${ }^{5,6}$

\begin{abstract}
Background: Results from a phase III, randomized, double-blind, active comparator-controlled, parallel-group trial evaluating fosaprepitant for the prevention of chemotherapy-induced nausea and vomiting (CINV) found that a single-day, triple-antiemetic fosaprepitant regimen resulted in a significantly higher proportion of patients achieving a complete response (CR; no vomiting or rescue medication use) in the delayed phase (25-120 h after chemotherapy initiation), compared with a 3-day control regimen (ClinicalTrials.gov, NCT01594749). As the risk for CINV is dependent on chemotherapy regimen and generally guided by tumor type, this post hoc analysis evaluated the efficacy and safety of this regimen by cancer subpopulations (gastrointestinal [GI] or colorectal, lung, breast, and gynecologic cancers).

Methods: Subjects with confirmed cancer who were naive to highly and moderately emetogenic chemotherapy (HEC and MEC) and were scheduled to receive intravenous (IV) anthracycline-cyclophosphamide (AC)-based MEC on the first day of chemotherapy were randomly assigned to receive oral ondansetron and oral dexamethasone plus either a single IV dose of fosaprepitant $150 \mathrm{mg}$ (fosaprepitant regimen) or placebo (control regimen). The primary efficacy end point was the proportion of subjects achieving $C R$ in the delayed phase. CR rates in the overall and acute phases (0-120 h and 0-24 h after MEC initiation, respectively) were assessed as secondary end points. Safety and tolerability were also assessed.

(Continued on next page)
\end{abstract}

* Correspondence: cindy.I.weinstein@merck.com

${ }^{1}$ Merck \& Co., Inc., 2000 Galloping Hill Road, Kenilworth, NJ, USA

Full list of author information is available at the end of the article

C The Author(s). 2020 Open Access This article is licensed under a Creative Commons Attribution 4.0 International License, which permits use, sharing, adaptation, distribution and reproduction in any medium or format, as long as you give appropriate credit to the original author(s) and the source, provide a link to the Creative Commons licence, and indicate if changes were made. The images or other third party material in this article are included in the article's Creative Commons licence, unless indicated otherwise in a credit line to the material. If material is not included in the article's Creative Commons licence and your intended use is not permitted by statutory regulation or exceeds the permitted use, you will need to obtain permission directly from the copyright holder. To view a copy of this licence, visit http://creativecommons.org/licenses/by/4.0/. The Creative Commons Public Domain Dedication waiver (http://creativecommons.org/publicdomain/zero/1.0/) applies to the data made available in this article, unless otherwise stated in a credit line to the data. 
(Continued from previous page)

Results: CR rates in the delayed phase favored the fosaprepitant regimen over the control regimen across the Gl/ colorectal, lung, breast, and gynecologic cancer subgroups (range, 6.2-22\%); similar findings were observed for CR in the overall phase. CR in the acute phase was high for all groups ( $\geq 87 \%)$. The fosaprepitant regimen was well tolerated in all cancer subgroups.

Conclusions: This post hoc analysis indicated that a single-day fosaprepitant regimen was effective in preventing CINV in patients receiving MEC, regardless of cancer type.

Trial registration: ClinicalTrials.gov NCT01594749, registered May 9, 2012.

Keywords: Chemotherapy-induced nausea and vomiting (CINV), Fosaprepitant, Gastrointestinal cancer, Lung cancer, Breast cancer, Gynecologic cancer

\section{Background}

The prevention of chemotherapy-induced nausea and vomiting (CINV), a common and potentially treatmentlimiting side effect of cancer therapy, remains an important challenge [1-3]. Since CINV risk factors depend mainly on chemotherapy regimen, which is generally guided by tumor type (e.g., National Comprehensive Cancer Network cancer treatment regimens), antiemetic requirements may differ across tumor types. The emetic risk of agents considered to be moderately emetogenic chemotherapy (MEC) ranges from 30 to $90 \%$, and the risk for those considered to be highly emetogenic chemotherapy (HEC) is $>90 \%$ [4-6]. Estimating the emetic risk of multiagent chemotherapy regimens is more challenging; tools have been devised to estimate the emetogenicity of multiagent chemotherapy regimens $[7,8]$. Current guidelines recommend prescribing antiemetics based on the chemotherapy agent with the highest emetogenic risk [6].

Neurokinin-1 receptor antagonists have been extensively studied and incorporated into treatment guidelines in various combinations with other antiemetic agents for prevention of CINV from MEC therapy [4, 6, 9]. The National Comprehensive Cancer Network recommends this drug class for MEC-induced CINV generally, and specific recommendations in other guidelines include adults treated with carboplatin (drug class) [4, 9] and children who are unable to tolerate dexamethasone (aprepitant) [9]. These recommendations have been supported by multiple phase III trials, including the study of fosaprepitant we present in this article $[4,6,9]$.

Fosaprepitant is a neurokinin-1 receptor antagonist that is indicated in adults and children aged 6 months and older, in combination with other antiemetic agents, for the prevention of acute and delayed nausea and vomiting associated with initial and repeat courses of HEC and delayed nausea and vomiting associated with initial and repeat courses of MEC [10].

PN031 was a phase III, randomized, double-blind, active comparator-controlled, parallel-group trial that investigated the efficacy and safety of a single-dose, triple- antiemetic, fosaprepitant regimen for the prevention of CINV in patients $(N=1000)$ receiving non-anthracycline-cyclophosphamide (AC)-based MEC with any type of malignancy [11]. AC regimens, although traditionally considered MEC, were reclassified as HEC in 2011 because of their propensity to induce CINV, particularly nausea, in patients with breast cancer [12-14] and were thus excluded. The primary end point of PN031 was met, with the single-day fosaprepitant regimen demonstrating a significant improvement in the proportion of patients achieving a CR (no vomiting or rescue medication use) in the delayed phase (25-120 h after MEC initiation), compared with the 3-day control regimen [11].

Because chemotherapy regimens and emetogenic risk vary based on the type of cancer, it is important to evaluate the ability of antiemetic regimens to prevent CINV in different patient populations. Herein, we report the results of a post hoc analysis of PN031, which evaluated the efficacy of a single-day fosaprepitant regimen compared with a standard 3-day control regimen in the most common cancer subpopulations in the study (ie, gastrointestinal [GI] or colorectal, lung, breast, and gynecologic).

\section{Methods \\ Study design and population}

The current report is a post hoc analysis based on data from a phase III, multicenter, global, double-blind, randomized trial (PN031) [11]. Details of the study entry criteria have been published previously [11] (ClinicalTrials.gov identifier: NCT01594749).

In brief, adult subjects with histologically or cytologically confirmed cancer who were naive to HEC and MEC and were scheduled to receive $\geq 1$ IV dose of non-AC MEC on day 1 were included [11]. Major exclusion criteria included the following: vomiting in the 24-h period before day 1; symptomatic primary or metastatic central nervous system malignancy causing nausea and/ or vomiting; and use of any dose of cisplatin or other HEC [11]. 
The trial adhered to the International Conference on Harmonization Good Clinical Practice guidelines and was conducted in agreement with the Declaration of Helsinki. The protocol was approved by health authorities and ethics committees/institutional review boards prior to study initiation for all participating study centers. All subjects were required to provide written informed consent before study enrollment.

\section{Study treatments}

Study treatments have been described in detail previously [11] and are summarized here. Subjects were randomly assigned 1:1 to a single IV dose of fosaprepitant $150 \mathrm{mg}$ (fosaprepitant regimen) or placebo (control regimen), administered approximately $30 \mathrm{~min}$ before MEC initiation on day 1 . Both treatment groups received oral ondansetron plus oral dexamethasone on day 1 before MEC, followed by oral ondansetron $8 \mathrm{~h}$ later. Subjects in the control group also received ondansetron every $12 \mathrm{~h}$ on days 2 and 3; the fosaprepitant group received matching placebo on these days. Investigator-prescribed rescue medication was permitted throughout the study.

\section{Study outcomes}

The proportion of subjects who achieved CR during the delayed phase served as the primary efficacy end point. Secondary efficacy end points included: the proportion of subjects achieving CR during the overall (0-120 h after MEC initiation) and acute phases (0-24h after MEC initiation); and the proportion of subjects with no vomiting (no emetic episodes, including no vomit [expulsion of stomach contents through the mouth] and no retching or dry heaves [an attempt to vomit that is not productive of stomach contents], regardless of use of rescue medication) during the overall phase.

National Cancer Institute Common Terminology Criteria for Adverse Events, version 4.0 was used to assess adverse events (AEs). Events that the investigator considered to be related to any of the study medications were recorded as treatment-related AEs.

\section{Statistical analysis}

Efficacy analyses included participants who received $\geq 1$ dose of study drug and in accordance with the intention-to-treat (ITT) principle were analyzed in their randomly assigned treatment group. Safety analyses following the all-subjects-as-treated (ASaT) approach included participants who received $\geq 1$ dose of study drug and who were analyzed in the treatment group based on the drug actually received. The primary and secondary efficacy end points were explored for the ITT population in the most commonly reported cancer subpopulations for PN031, which were GI or colorectal, lung, breast, and gynecologic cancer. Treatment group comparisons were made using the Cochran-Mantel-Haenszel test [15] (stratified by sex) and 95\% confidence intervals (CIs) calculated by the Miettinen-Nurminen method [16]. Time-to-first vomiting episode was analyzed using the Kaplan-Meier method [17]. Demographic variables, baseline characteristics, and AEs were summarized with descriptive statistics.

With a sample size of 80 subjects from each subgroup, the power to detect the $20 \%$ difference in complete response between groups is $73 \%$ with a $5 \%$ two-sided significance level. In other words, the sample sizes are adequate for some group comparisons. For smaller subgroups by chemotherapy, there was no formal testing. This post hoc presentation is provided for descriptive purposes only.

\section{Results}

Subjects

The overall ITT population included 1000 subjects, which comprised 502 subjects assigned to the fosaprepitant regimen and 498 assigned to the control regimen. The most common cancer subgroups included (ASaT population) GI or colorectal cancer $(n=267$; fosaprepitant regimen, $n=135$, and control regimen, $n=132$ ); lung cancer ( $n=254$; fosaprepitant regimen, $n=130$, and control regimen, $n=124)$; breast cancer $(n=231$; fosaprepitant regimen, $n=110$, and control regimen, $n=$ $121)$; and gynecologic cancer $(n=152$; fosaprepitant regimen, $n=81$, and control regimen, $n=71$ ). The following cancer subgroups had too few patients for analysis: head and neck cancer $(n=21$; fosaprepitant regimen, $n=12$; control regimen, $n=9)$, germ cell cancer $(n=2$; fosaprepitant regimen, $n=0$; control regimen, $n=2)$, hepatobiliary cancer $(n=8$; fosaprepitant regimen, $n=2$; control regimen, $n=6$ ), lymphoproliferative cancer ( $n=8$; fosaprepitant regimen, $n=4$; control regimen, $n=4)$, sarcoma $(n=9 ;$ fosaprepitant regimen, $n=5$; control regimen, $n=4)$, skin cancer $(n=3$; fosaprepitant regimen, $n=1$; control regimen, $n=2)$, and unspecified other types $(n=45$; fosaprepitant regimen, $n=23$; control regimen, $n=22$ ). Baseline characteristics and CINV prognostic factors were generally well balanced between the treatment groups within cancer subgroups (Table 1).

\section{Cancer subgroup chemotherapy regimens}

Chemotherapy regimens that were used across the analyzed cancer subgroups are summarized in Table 2 .

In the GI or colorectal cancer subgroup, the majority of subjects received multiple-day chemotherapy regimens in the fosaprepitant and control regimen treatment arms (77.8 and $82.6 \%$, respectively); single-day regimens were used by 20.7 and $15.9 \%$ of subjects, respectively. Most subjects in this cancer subgroup received noncarboplatin-based MEC; only 5 subjects in each 
Table 1 Demographics and baseline characteristics (ASaT population)

\begin{tabular}{|c|c|c|c|c|c|c|c|c|}
\hline & \multicolumn{4}{|c|}{ Fosaprepitant regimen } & \multicolumn{4}{|l|}{ Control regimen } \\
\hline & $\begin{array}{l}\text { Gl or colorectal } \\
\text { cancers } \\
(n=135)\end{array}$ & $\begin{array}{l}\text { Lung } \\
\text { cancer } \\
(n=130)\end{array}$ & $\begin{array}{l}\text { Breast } \\
\text { cancer } \\
(n=110)\end{array}$ & $\begin{array}{l}\text { Gynecologic } \\
\text { cancer } \\
(n=81)\end{array}$ & $\begin{array}{l}\text { Gl or colorectal } \\
\text { cancers } \\
(n=132)\end{array}$ & $\begin{array}{l}\text { Lung cancer } \\
(n=124)\end{array}$ & $\begin{array}{l}\text { Breast } \\
\text { cancer } \\
(n=121)\end{array}$ & $\begin{array}{l}\text { Gynecologic } \\
\text { cancer } \\
(n=71)\end{array}$ \\
\hline \multicolumn{9}{|l|}{ Age, years } \\
\hline Median (range) & $62(24-85)$ & $65(36-82)$ & $57(28-78)$ & $58(31-88)$ & $60(23-88)$ & $65(38-82)$ & $54(28-81)$ & $56(24-78)$ \\
\hline \multicolumn{9}{|l|}{ Age group, $n(\%)$} \\
\hline$<50$ years & $21(15.6)$ & $7(5.4)$ & 37 (33.6) & $25(30.9)$ & $21(15.9)$ & $5(4.0)$ & $39(32.2)$ & $24(33.8)$ \\
\hline$\geq 50$ years & $114(84.4)$ & $123(94.6)$ & $73(66.4)$ & $56(69.1)$ & $111(84.1)$ & $119(96.0)$ & $82(67.8)$ & $47(66.2)$ \\
\hline \multicolumn{9}{|l|}{ Sex, $n(\%)$} \\
\hline Male & $86(63.7)$ & $90(69.2)$ & $1(0.9)$ & 0 & $76(57.6)$ & $90(72.4)$ & 0 & 0 \\
\hline Female & 49 (36.3) & $40(30.8)$ & $109(99.1)$ & $81(100)$ & $56(42.4)$ & $34(27.4)$ & $121(100)$ & $71(100)$ \\
\hline $\begin{array}{l}\text { History of motion } \\
\text { sickness, } n(\%)\end{array}$ & $8(5.9)$ & $5(3.8)$ & $5(4.5)$ & $8(9.9)$ & $3(2.3)$ & $4(3.2)$ & $12(9.9)$ & $9(12.7)$ \\
\hline $\begin{array}{l}\text { History of emesis } \\
\text { during pregnancy, } \\
n(\%)\end{array}$ & $11(8.1)$ & $7(5.4)$ & $24(21.8)$ & $15(18.5)$ & $15(11.4)$ & $6(4.8)$ & $23(19.0)$ & $15(21.1)$ \\
\hline $\begin{array}{l}\text { History of alcohol } \\
\text { use, } n(\%)\end{array}$ & $69(51.1)$ & $68(52.3)$ & 35 (31.8) & $30(37.0)$ & $58(43.9)$ & $67(54.0)$ & 41 (33.9) & $21(29.6)$ \\
\hline $\begin{array}{l}\text { Chemotherapy } \\
\text { regimen, } n(\%)^{a}\end{array}$ & $n=135$ & $n=129$ & $n=110$ & $n=81$ & $n=132$ & $n=125$ & $n=121$ & $n=71$ \\
\hline Single day & $28(20.7)$ & $108(83.7)$ & $100(90.9)$ & $81(100)$ & $21(15.9)$ & $109(87.2)$ & $110(90.9)$ & $69(97.2)$ \\
\hline Multiple day & $105(77.8)$ & $18(14.0)$ & 0 & 0 & 109 (82.6) & $14(11.2)$ & 0 & $2(2.8)$ \\
\hline
\end{tabular}

ASaT all-subjects-as-treated, Gl gastrointestinal

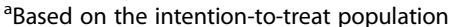

Table 2 Subject characteristics by chemotherapy categories (ITT population)

\begin{tabular}{|c|c|c|c|c|c|c|c|c|}
\hline \multirow[b]{2}{*}{$n(\%)$} & \multicolumn{4}{|c|}{ Fosaprepitant regimen } & \multicolumn{4}{|l|}{ Control regimen } \\
\hline & $\begin{array}{l}\text { Gl or colorectal } \\
\text { cancers }(n=135)\end{array}$ & $\begin{array}{l}\text { Lung } \\
\text { cancer } \\
(n=129)\end{array}$ & $\begin{array}{l}\text { Breast } \\
\text { cancer } \\
(n=110)\end{array}$ & $\begin{array}{l}\text { Gynecologic } \\
\text { cancer }(n=81)\end{array}$ & $\begin{array}{l}\text { Gl or colorectal } \\
\text { cancers }(n=132)\end{array}$ & $\begin{array}{l}\text { Lung } \\
\text { cancer } \\
(n=125)\end{array}$ & $\begin{array}{l}\text { Breast } \\
\text { cancer } \\
(n=121)\end{array}$ & $\begin{array}{l}\text { Gynecologic } \\
\text { cancer }(n=71)\end{array}$ \\
\hline \multicolumn{9}{|l|}{ Single-day regimens } \\
\hline Single MEC & $4(3.0)$ & $12(9.3)$ & $10(9.1)$ & $9(11.1)$ & $4(3.0)$ & $21(16.8)$ & $3(2.5)$ & $7(9.9)$ \\
\hline $\mathrm{MEC}+\geq 1 \mathrm{LEC}$ & $24(17.8)$ & $96(74.4)$ & $90(81.8)$ & $72(89)$ & $16(12.1)$ & $88(70.4)$ & $106(87.6)$ & $61(85.9)$ \\
\hline $\mathrm{MEC}+\mathrm{MEC}$ & 0 & 0 & 0 & 0 & $1(0.8)$ & 0 & $1(0.8)$ & $1(1.4)$ \\
\hline \multicolumn{9}{|l|}{ Multiple-day regimens } \\
\hline $\begin{array}{l}\text { MEC (day } 1)+\geq 1 \text { LEC } \\
\text { beyond day } 1\end{array}$ & $100(74.1)$ & $18(14.0)$ & 0 & 0 & $94(71.2)$ & $14(11.2)$ & 0 & $2(2.8)$ \\
\hline $\begin{array}{l}\text { MEC (day 1) }+\geq 1 \text { MEC } \\
+\geq 1 \text { LEC }\end{array}$ & $5(3.7)$ & 0 & 0 & 0 & $15(11.4)$ & 0 & 0 & 0 \\
\hline \multicolumn{9}{|c|}{ Non-MEC regimens or no MEC on day 1} \\
\hline LEC only & $2(1.5)$ & 0 & $8(7.3)$ & 0 & $2(1.5)$ & $1(0.8)$ & $8(6.6)$ & 0 \\
\hline $\begin{array}{l}\text { Chemotherapy on } \\
\text { day } 2 \text { only }^{\mathrm{a}}\end{array}$ & 0 & 0 & 0 & 0 & 0 & 0 & 0 & 0 \\
\hline HEC regimens & 0 & $3(2.3)$ & $2(1.8)$ & 0 & 0 & $1(0.8)$ & $3(2.5)$ & 0 \\
\hline Cisplatin-based & - & $3(2.3)$ & - & - & - & $1(0.8)$ & - & - \\
\hline AC-based & - & - & $2(1.8)$ & - & - & - & $3(2.5)$ & - \\
\hline
\end{tabular}

$A C$ anthracycline + cyclophosphamide, HEC highly emetogenic chemotherapy, ITT intent to treat, LEC low emetogenic chemotherapy, MEC moderately emetogenic chemotherapy

${ }^{\text {a }}$ Subject received MEC + LEC on day 2 
treatment arm received carboplatin-based chemotherapy. Within the non-carboplatin-based MEC regimens, oxaliplatin or irinotecan alone or in combination with other antineoplastic agents (of a heterogenous emetogenic potential) were received by all but 5 subjects ( 3 in the fosaprepitant arm, 2 in the control arm).

In the lung cancer subgroup, most subjects received single-day MEC regimens, comprising primarily MEC plus one or more low emetogenic chemotherapy (LEC) agent(s) (74.4 and $70.4 \%$ subjects for the fosaprepitant and control regimens, respectively). Multiple-day regimens were received by $18(14.0 \%)$ and 14 (11.2\%) subjects, respectively. Nearly all participants (98\%), regardless of chemotherapy duration, received a carboplatin-containing regimen.

In the breast cancer subgroup, most subjects received single-day MEC regimens $(90.9 \%$ in both treatment groups); overall, $84.8 \%$ received a MEC plus one or more LEC regimen. No subjects received multipleday chemotherapy regimens. The most commonly used regimens were those containing cyclophosphamide $(47.6 \%$ received cyclophosphamide with a LEC or MEC agent).

In the gynecologic cancer subgroup, all but 2 subjects (both in the control regimen) received single-day MEC regimens. Most subjects received carboplatin-based chemotherapy ( 93.8 and $93.0 \%$ of subjects in the fosaprepitant and control groups, respectively).

\section{Complete response rates by cancer subgroup}

The percentages of subjects achieving CR in the delayed phase were higher with the fosaprepitant regimen, compared with the control regimen across all cancer subgroups (Fig. 1a-d). Treatment differences in CR rates between the fosaprepitant and control regimens in the delayed phase were $8.0 \%$ for GI or colorectal cancers, $6.2 \%$ for lung cancer, $7.8 \%$ for breast cancer, and $22.0 \%$ for gynecologic cancer.

Similar findings were also observed for treatment differences in $\mathrm{CR}$ rates in the overall phase $(8.1,6.2,5.9$, and $22.1 \%$, respectively), whereas $\mathrm{CR}$ rates in the acute phase were high $(>87 \%)$ in both treatment arms for all cancer subtypes with no notable treatment differences (4.0, $-0.6,0.0$, and 5.1\%, respectively) (Fig. 1a-d).

\section{No vomiting episodes by cancer subgroups}

The percentages of subjects with no vomiting in the delayed, overall, and acute phases are summarized in Fig. 2a-d. In the GI or colorectal cancer subgroup, higher rates were observed with the fosaprepitant regimen versus the control regimen during all 3 phases; the greatest treatment difference between the fosaprepitant and control regimens was seen during the overall phase (10.2\%). In the lung cancer subgroup, numerically higher rates were observed with the fosaprepitant regimen versus the control regimen during the delayed and overall
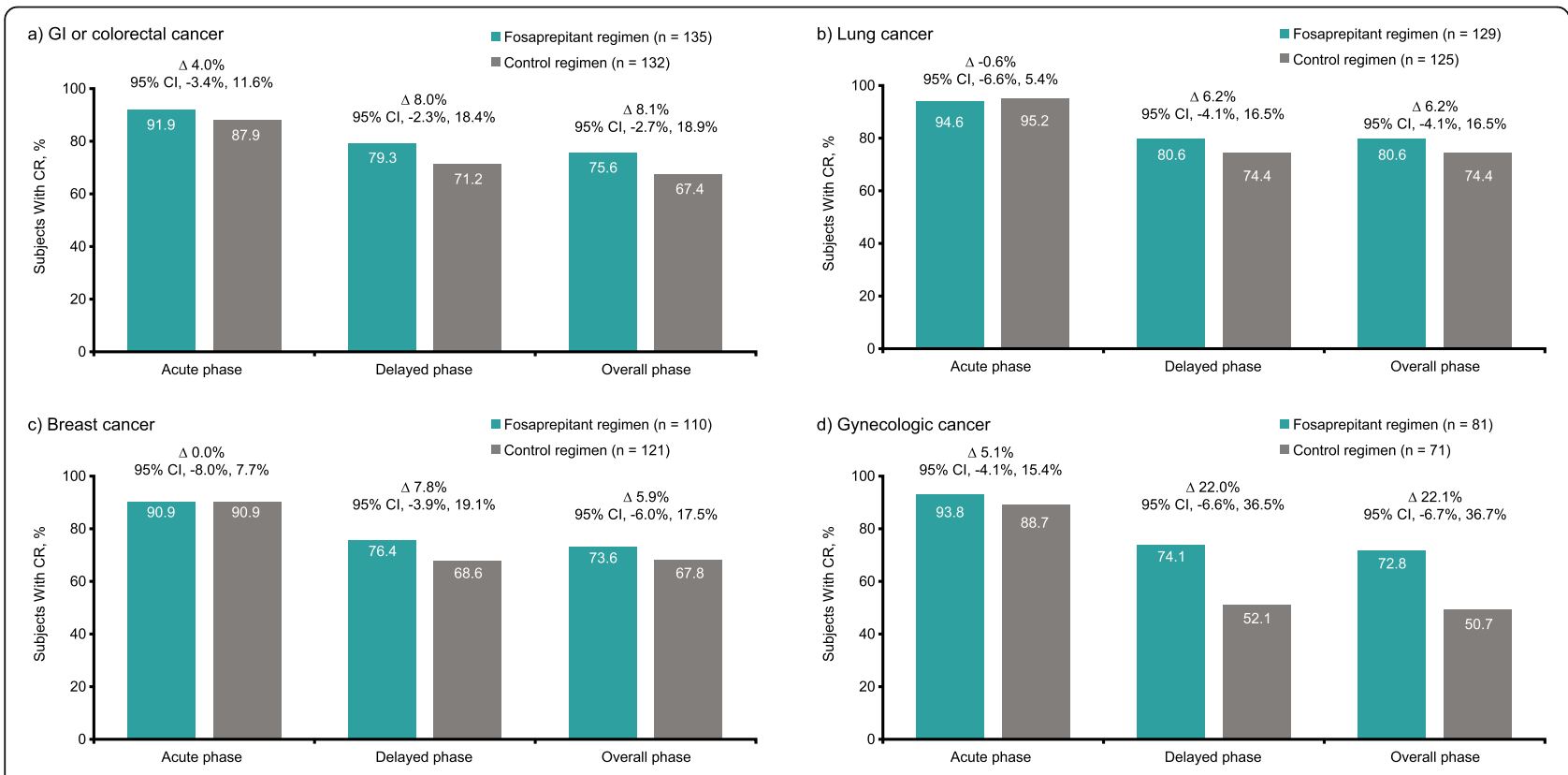

Fig. 1 Proportion of subjects achieving a CR for the fosaprepitant regimen versus the control regimen: acute (0-24 h), delayed (25-120 h), and overall (0-120 h) CR rates based on the Cochran-Mantel-Haenszel method, with stratification by sex (ITT population). a Subjects with Gl or colorectal cancer. b Subjects with lung cancer. c Subjects with breast cancer. d Subjects with gynecologic cancer. Cl confidence interval, CR complete response, Gl gastrointestinal, ITT intention-to-treat 

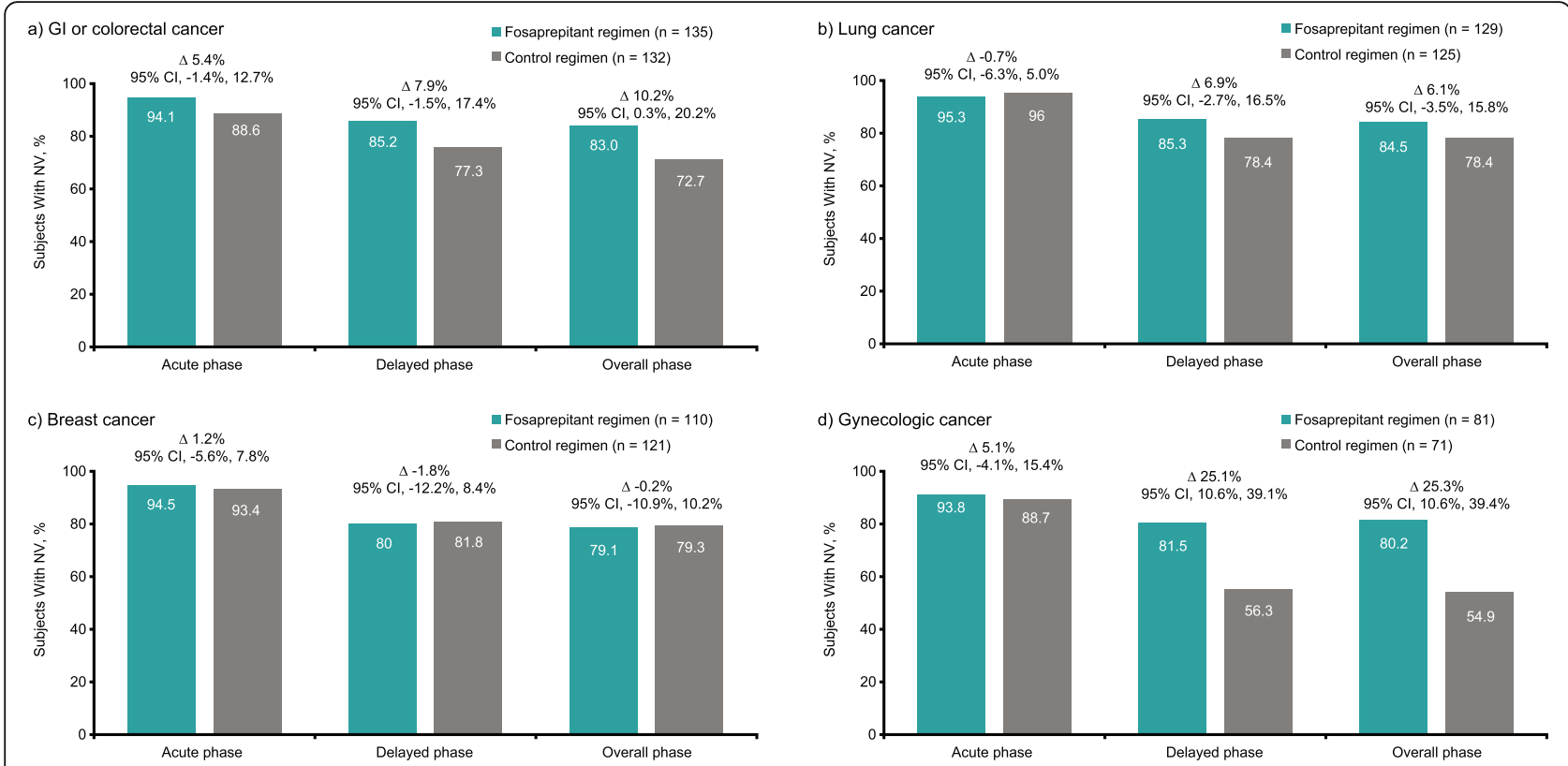

Fig. 2 Proportion of subjects achieving no vomiting for the fosaprepitant regimen versus the control regimen: acute (0-24 h), delayed (25-120 h), and overall (0-120 h) no vomiting rates based on the Cochran-Mantel-Haenszel method, with stratification by sex (ITT population). a Subjects with Gl or colorectal cancer. b Subjects with lung cancer. c Subjects with breast cancer. d Subjects with gynecologic cancer. Cl confidence interval, Gl gastrointestinal, ITT intention-to-treat, NV no vomiting

phases; similar rates were seen between treatment groups in the acute phase. Similar rates between the fosaprepitant and control regimens were reported in all 3 phases for patients in the breast cancer subgroup. Finally, higher rates were observed with the fosaprepitant regimen versus the control regimen during all 3 phases in the gynecologic cancer subgroup.

\section{Time-to-first vomiting episode by cancer subgroups}

Kaplan-Meier analyses indicated that the time-to-first vomiting episode was delayed in the fosaprepitant regimen group, compared with the control regimen group in all cancer subgroups; however, differences in the subgroup of subjects with breast cancer were small (Fig. 3a-d).

\section{Safety by cancer subgroup}

The fosaprepitant regimen was generally well tolerated across all cancer subgroups. The proportions of subjects with at least $1 \mathrm{AE}$ and with at least 1 treatment-related $\mathrm{AE}$ by cancer subgroup were similar between the fosaprepitant and control regimens for all subgroups. AEs appeared to be well balanced between treatment groups across all cancer subgroups; the most common grade 1-4 AEs are summarized in Table 3. Diarrhea was the most commonly observed $\mathrm{AE}$ in the $\mathrm{GI}$ or colorectal cancer subgroups (18.5 and 17.4\%), fatigue was the most commonly observed $\mathrm{AE}$ in subjects with lung cancer (13.1 and 9.7\%) and gynecologic cancer (12.3 and
$14.1 \%)$, for the fosaprepitant and control regimens, respectively. In the breast cancer subgroup, neutropenia, fatigue, and diarrhea were observed most frequently.

In the breast cancer subgroup, 1 serious treatmentrelated AE (hypersensitivity) was reported in the fosaprepitant regimen, which resolved after $30 \mathrm{~min}$. Two serious treatment-related AEs (hypersensitivity and constipation) were also reported in the control group of the gynecologic cancer subgroup.

Ten subjects died during the study. Death was rare in both the fosaprepitant and control regimen treatment arms in the GI or colorectal (1.5 and 0\%, respectively), lung (3.8 and 1.6\%, respectively), breast (both $0 \%$ ), and gynecologic (1.2 and 0\%, respectively) cancer subgroups. All deaths during the study appeared to be attributable to subjects' underlying malignancies, other preexisting conditions, and/or effects of chemotherapy, and none of the deaths were considered related to the study drug by the investigators.

\section{Discussion}

The results of this post hoc analysis of the PN031 trial showed consistent efficacy of a single-day fosaprepitant regimen across common cancer subpopulations, including GI or colorectal, lung, breast, and gynecologic cancers. Compared with ondansetron plus dexamethasone alone (control regimen), the addition of fosaprepitant led to a greater proportion of subjects achieving CR across cancer subtypes in the delayed phase, with the largest treatment 

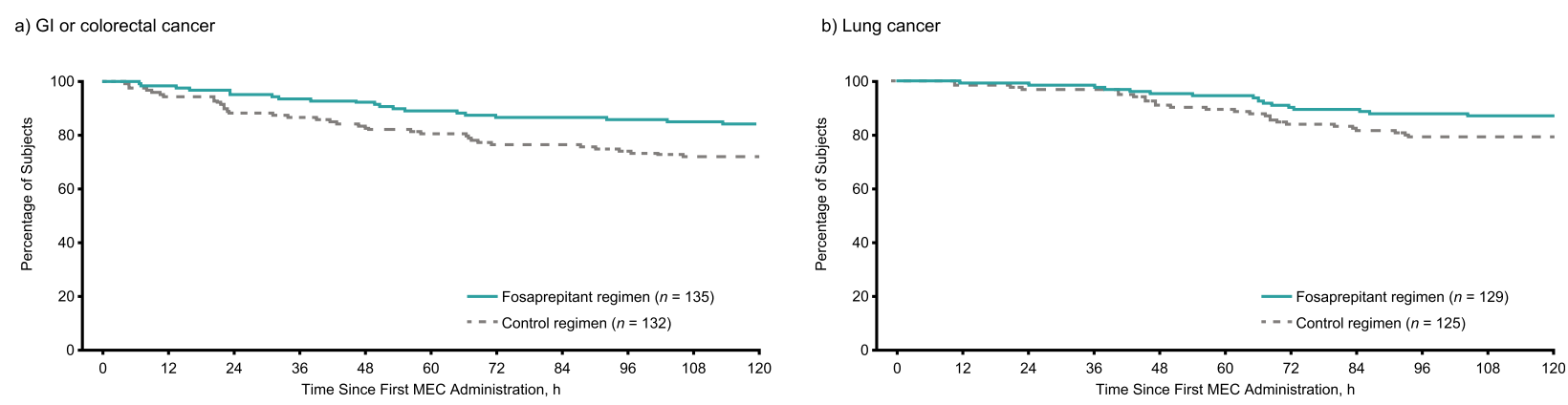

c) Breast cancer

d) Gynecologic cancer
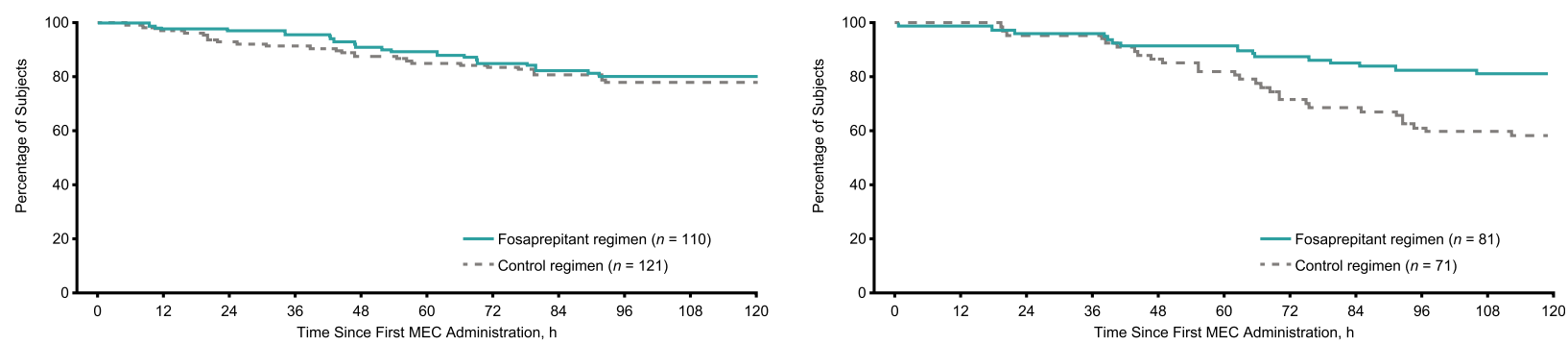

Fig. 3 Kaplan-Meier curves of time to first vomiting episode from the first initiation of MEC for the fosaprepitant regimen versus the control regimen during the overall (0-120 h) phase (ITT population). a Subjects with Gl or colorectal cancer. b Subjects with lung cancer. c Subjects with breast cancer. d Subjects with gynecologic cancer. Gl gastrointestinal, ITT intent-to-treat, MEC moderately emetogenic chemotherapy

difference being observed in the subgroup of subjects with gynecologic cancer (22\%). In the acute phase, both groups had good antiemetic control across cancer subgroups. Furthermore, time-to-first vomiting episode favored fosaprepitant across all cancer subgroups.

Cancer subgroup treatment response may be affected by chemotherapy type, chemotherapy duration, and predictive risk factors. In a recent publication outlining the development of a tool for the assessment of predictive risk factors of CINV, 8 risk factors were identified: patient age $\leq 60$ years, the first cycle of chemotherapy, presence of anticipatory nausea and vomiting, a history of morning sickness, having fewer than $7 \mathrm{~h}$ of sleep the night before chemotherapy, CINV in the prior cycle, patient self-medication with nonprescribed antiemetics, and the use of platinum-based or AC-based regimens [18]. While all subjects were receiving non-AC MEC in the current analysis, the subjects in the gynecologic cancer subgroup were more commonly treated with carboplatin-based chemotherapy, which tends to have a higher risk of inducing CINV than noncarboplatin chemotherapy $[6,9]$, compared with the other cancer subtypes. This may explain, in part, why the largest treatment difference for CR (22\%) was observed in this subgroup. The GI/colorectal cancer subgroup received more multiple-day than single-day chemotherapy regimens compared with the other cancer subgroups, which may have contributed to early divergence in time to vomiting in this cancer subgroup.
In an earlier exploratory analysis of this study, the effects of chemotherapy type (carboplatin-based vs. non-carboplatin-based) and chemotherapy duration (single-day vs. multiple-day) across all cancer subtypes were explored. That report found that the chemotherapy type and duration did not appear to influence response to fosaprepitant [19]. Whether subjects received either single- or multiple-day MEC regimens, or carboplatinbased or non-carboplatin-based chemotherapy regimens did not substantially affect $\mathrm{CR}$ rates with the fosaprepitant regimen, and $\mathrm{CR}$ was consistent $(76-80 \%)$ during both the delayed and overall phases. However, compared with the control regimen, fosaprepitant exhibited more favorable treatment effects in the delayed phase of the carboplatin-based versus the non-carboplatin-based subgroup $(14.1 \%$ vs. $6.5 \%)$, as well as for the single-day versus the multiple-day subgroup ( $13.2 \%$ vs. $3.2 \%)$. Fosaprepitant also exhibited more favorable treatment effects over control in the single-day versus the multiple-day treatment group in the overall phase $(12.8 \%$ vs. $4.0 \%)$ [19]. This suggests that the treatment effect of the fosaprepitant regimen may be more pronounced in subjects receiving carboplatin-based and single-day chemotherapeutic regimens.

Previous studies have evaluated a range of cancer subpopulations in subjects receiving MEC and HEC (ie, including approximately 50\% AC-based) regimens. Post hoc subanalyses of clinical trials investigating a rolapitant regimen (including a $5 \mathrm{HT}_{3} \mathrm{RA}$ and dexamethasone) 
Table 3 Summary of the most common ( $\geq 5 \%$ ) adverse events ${ }^{\mathrm{a}}$ (ASaT population)

\begin{tabular}{|c|c|c|c|c|c|c|c|c|}
\hline \multirow[b]{2}{*}{$A E, n(\%$} & \multicolumn{4}{|c|}{ Fosaprepitant regimen } & \multicolumn{4}{|l|}{ Control regimen } \\
\hline & $\begin{array}{l}\text { Gl or colorectal } \\
\text { cancers }(n=135)\end{array}$ & $\begin{array}{l}\text { Lung } \\
\text { cancer } \\
(n=130)\end{array}$ & $\begin{array}{l}\text { Breast } \\
\text { cancer } \\
(n=110)\end{array}$ & $\begin{array}{l}\text { Gynecologic } \\
\text { cancer }(n=81)\end{array}$ & $\begin{array}{l}\text { Gl or colorectal } \\
\text { cancers }(n=132)\end{array}$ & $\begin{array}{l}\text { Lung } \\
\text { cancer } \\
(n=124)\end{array}$ & $\begin{array}{l}\text { Breast } \\
\text { cancer } \\
(n=121)\end{array}$ & $\begin{array}{l}\text { Gynecologic cancer } \\
(n=71)\end{array}$ \\
\hline Any & $83(61.5)$ & $73(56.2)$ & $86(78.2)$ & $41(50.6)$ & $80(60.6)$ & $66(53.2)$ & $88(72.7)$ & $42(59.2)$ \\
\hline Neutropenia & $2(1.5)$ & $7(5.4)$ & $27(24.5)$ & $3(3.7)$ & $1(0.8)$ & $5(4.0)$ & $23(19.0)$ & $5(7.0)$ \\
\hline Diarrhea & $25(18.5)$ & $8(6.2)$ & $19(17.3)$ & $5(6.2)$ & $23(17.4)$ & $4(3.2)$ & $24(19.8)$ & $4(5.6)$ \\
\hline Fatigue & 18 (13.3) & $17(13.1)$ & $26(23.6)$ & $10(12.3)$ & $13(9.8)$ & $12(9.7)$ & $25(20.7)$ & $10(14.1)$ \\
\hline Constipation & $18(13.3)$ & $7(5.4)$ & $12(10.9)$ & $8(9.9)$ & $10(7.6)$ & $10(8.1)$ & $20(16.5)$ & $8(11.3)$ \\
\hline Headache & $11(8.1)$ & $4(3.1)$ & $12(10.9)$ & $2(2.5)$ & $12(9.1)$ & $3(2.4)$ & 16 (13.2) & $2(2.8)$ \\
\hline Decreased appetite & $11(8.1)$ & $5(3.8)$ & $5(4.5)$ & $5(6.2)$ & $11(8.3)$ & $7(5.6)$ & $10(8.3)$ & $3(4.2)$ \\
\hline Dysgeusia & $4(3.0)$ & $3(2.3)$ & $9(8.2)$ & $2(2.5)$ & $7(5.3)$ & 0 & $13(10.7)$ & $1(1.4)$ \\
\hline Arthralgia & $2(1.5)$ & $4(3.1)$ & $6(5.5)$ & $6(7.4)$ & $2(1.5)$ & $6(4.8)$ & $6(5.0)$ & $4(5.6)$ \\
\hline Peripheral neuropathy & $10(7.4)$ & $1(0.8)$ & 0 & $1(1.2)$ & $5(3.8)$ & 0 & $2(1.7)$ & $4(5.6)$ \\
\hline Bone pain & 0 & 0 & $8(7.3)$ & 0 & $1(0.8)$ & $3(2.4)$ & $6(5.0)$ & 0 \\
\hline Abdominal pain & $8(5.9)$ & $2(1.5)$ & $2(1.8)$ & $1(1.2)$ & $6(4.5)$ & $1(0.8)$ & $3(2.5)$ & $3(4.2)$ \\
\hline Myalgia & $1(0.7)$ & $3(2.3)$ & $4(3.6)$ & $4(4.9)$ & $2(1.5)$ & $4(3.2)$ & $6(5.0)$ & $7(9.9)$ \\
\hline Alopecia & $2(1.5)$ & $2(1.5)$ & $5(4.5)$ & $2(2.5)$ & $3(2.3)$ & $5(4.0)$ & $13(10.7)$ & $4(5.6)$ \\
\hline Asthenia & $6(4.4)$ & $7(5.4)$ & $3(2.7)$ & $2(2.5)$ & $9(6.8)$ & $3(2.4)$ & $1(0.8)$ & $1(1.4)$ \\
\hline Dizziness & $2(1.5)$ & $2(1.5)$ & $5(4.5)$ & $3(3.7)$ & $2(1.5)$ & $2(1.6)$ & $7(5.8)$ & 0 \\
\hline Febrile neutropenia & $1(0.7)$ & $1(0.8)$ & $5(4.5)$ & $2(2.5)$ & 0 & $3(2.4)$ & $7(5.8)$ & 0 \\
\hline Nausea & $4(3.0)$ & $5(3.8)$ & $3(2.7)$ & $4(4.9)$ & $10(7.6)$ & $5(4.0)$ & $2(1.7)$ & $3(4.2)$ \\
\hline Paresthesia & $6(4.4)$ & 0 & 0 & 0 & $8(6.1)$ & 0 & 0 & $1(1.4)$ \\
\hline Rash & $2(1.5)$ & $1(0.8)$ & $4(3.6)$ & $1(1.2)$ & 0 & $3(2.4)$ & $6(5.0)$ & 0 \\
\hline Decreased neutrophil count & 0 & $1(0.8)$ & $3(2.7)$ & 0 & 0 & 0 & $7(5.8)$ & $1(1.4)$ \\
\hline Stomatitis & $3(2.2)$ & $1(0.8)$ & $1(0.9)$ & $1(1.2)$ & $2(1.5)$ & $1(0.8)$ & $10(8.3)$ & 0 \\
\hline Dyspnea & $1(0.7)$ & $8(6.2)$ & 0 & 0 & $2(1.5)$ & 0 & $1(0.8)$ & 0 \\
\hline Musculoskeletal pain & 0 & $1(0.8)$ & $3(2.7)$ & $1(1.2)$ & 0 & $3(2.4)$ & $5(4.1)$ & $7(9.9)$ \\
\hline
\end{tabular}

$A E$ adverse event, $A S a T$ all-subjects-as-treated, Gl gastrointestinal

${ }^{\text {a }}$ Grades 1 to 4 by maximum toxicity grade in subjects within either treatment arm

evaluated CINV in specific cancer subtypes, including GI/colorectal, lung, and breast cancers [20, 21]. Their post hoc analysis of 84 subjects with GI or colorectal cancer who received MEC agents (predominantly irinotecan and oxaliplatin) reported higher $\mathrm{CR}$ rates among patients receiving a rolapitant regimen versus placebo in the acute $(91.5 \%$ vs. $73.0 \%)$, delayed $(74.5 \%$ vs. $54.1 \%)$, and overall phases $(74.5 \%$ vs. $48.6 \%)$. In subjects with lung cancer $(n=687)$ receiving cisplatin or carboplatin, improvements in CR rates were seen with rolapitant versus an active control in the acute $(88.4 \%$ vs. $81.7 \%)$, delayed $(77.4 \%$ vs. $65.1 \%)$, and overall $(75.4 \%$ vs. $63.1 \%)$ phases. Finally, in subjects with breast cancer $(n=845)$ who were receiving MEC or HEC (AC-based) regimens, $\mathrm{CR}$ rates were greater with rolapitant than with active control in the overall $(62.8 \%$ vs. $55.1 \%)$ and delayed phases $(66.7 \%$ vs. $59.8 \%)$ [20, 21]. While these post hoc analyses with rolapitant also support the antiemetic efficacy of a substance $\mathrm{P} /$ neurokinin-1 receptor antagonist for the prevention of CINV, the studies included a high proportion of HEC, including cisplatin and AC-based regimens, as well as carboplatin, whereas the PN031 study is a true MEC trial by current guideline definitions. However, the size of our current tumor type analysis of PN031 is smaller than the previously reported post hoc analyses of rolapitant studies, supporting the need for further investigation.

A pooled retrospective analysis of patient-level data from 4 large $(N=2813)$ randomized clinical trials of aprepitant was performed to characterize treatment response in subjects with various cancer subtypes (breast, GI, genitourinary, lung) who were receiving MEC and HEC (ACbased) regimens [22]. CR rates in subjects receiving MEC were higher for patients receiving aprepitant compared with those receiving the active control for all tumor types in the overall phase $(0-120 \mathrm{~h}$ after chemotherapy initiation), with the largest difference noted among patients with breast cancer (54.9\% vs. $43.9 \%)$. Although this 
retrospective analysis did not include a purely non-AC MEC population, the findings do further support the use of fosaprepitant in the MEC setting.

In the current analysis, the fosaprepitant regimen was generally well tolerated across all cancer subtypes. Serious treatment-related AEs were rare, and no deaths were considered related to the study drug. In general, the safety profile of the fosaprepitant regimen was consistent across all cancer subtypes, although AEs were most prevalent in the group with breast cancer, followed by GI or colorectal cancers. Most of the apparent differences between subgroups can be attributed to disease- or treatment-based toxicity, eg, nausea/vomiting and neutropenia in breast cancer [23] and nausea/vomiting and diarrhea in GI cancer [24].

Several study limitations should be considered when drawing conclusions from the results of the current analysis of PN031. Although the findings of this analysis support those of the primary study results [11], the current analysis was post hoc and exploratory. This analysis explored the efficacy and safety of the single-day fosaprepitant triple antiemetic regimen versus a 3-day active-control regimen in 4 tumor types. However, the tumor type comparisons are limited because of differences in antineoplastic agents and chemotherapy regimens, which may have varying degrees of emetogenic risk even within the context of MEC [4-6, 19]. Moreover, some cancer types that were represented in the trial population had sample sizes too small to analyze, among them head and neck cancer, germ cell cancer, hepatobiliary cancer, lymphoproliferative cancer, sarcoma, skin cancer, and other unspecified types. Finally, these findings should be interpreted with caution as sample sizes for some cancer subgroups were small.

\section{Conclusions}

Findings of the current post hoc analysis of this phase III trial support those of the primary study-a single-day fosaprepitant regimen is effective in preventing CINV in subjects receiving non-AC-based MEC. The fosaprepitant regimen was effective across the most common cancer subpopulations in our study sample (GI/colorectal, lung, breast, gynecologic). Because the primary goal of antiemetic therapy is to prevent the occurrence of CINV, the consistent efficacy observed with a single dose of fosaprepitant across different tumor types is encouraging. As a result, adequately powered, randomized controlled studies prospectively evaluating these cancer subpopulations are warranted.

\section{Supplementary information}

Supplementary information accompanies this paper at https://doi.org/10. 1186/s12885-020-07259-5.

Additional file 1. List of Independent Ethics Committees (IECs).

\section{Abbreviations}

AC: Anthracycline-cyclophosphamide; AE: Adverse event; ASaT: All subjects as treated; Cl: Confidence interval; CINV: Chemotherapy-induced nausea and vomiting; CR: Complete response; GI: Gastrointestinal; HEC: Highly emetogenic chemotherapy; ITT: Intention-to-treat; IV: Intravenous; LEC: Low emetogenic chemotherapy; MEC: Moderately emetogenic chemotherapy

\section{Acknowledgements}

Medical writing and editorial assistance were funded by Merck Sharp \& Dohme Corp., a subsidiary of Merck \& Co., Inc., Kenilworth, NJ, USA, and were provided by Maxwell Chang and Traci Stuve of ApotheCom (Yardley, PA).

\section{Authors' contributions}

CW participated in the study conception and/or design, data analysis and interpretation, drafting the manuscript and providing critical review of the manuscript for important intellectual content. $\mathrm{KJ}$ contributed to the data analysis and interpretation, drafting the manuscript and providing critical review of the manuscript for important intellectual content. SG participated in the study conception and/or design, data analysis and interpretation, and provided critical review and revision of the manuscript for important intellectual content. SK contributed to the acquisition and interpretation of data and provided critical review of the manuscript for important intellectual content. EBB contributed to the study conception and/or design, data acquisition, analysis and interpretation, and provided critical review of the manuscript for important intellectual content. WV contributed to the study conception and/or design and data acquisition, and participated in drafting and providing critical review of the manuscript for important intellectual content. AP participated in data analysis and interpretation and provided critical review of the manuscript for important intellectual content. SJN participated in data acquisition, analysis and interpretation, and provided critical review of the manuscript for important intellectual content. BLR participated in the study conception and/or design, data acquisition, and provided critical review and revision of the manuscript for important intellectual content. All authors read and approved the final manuscript and agree to be accountable for all aspects of the work and to ensure that questions related to the accuracy or integrity of the manuscript are appropriately investigated and resolved.

\section{Funding}

Funding for this research was provided by Merck Sharp \& Dohme Corp., a subsidiary of Merck \& Co., Inc., Kenilworth, NJ, USA. Employees of Merck \& Co., Inc., Kenilworth, NJ, USA, were involved in developing the study design, data collection, writing of the report, and the decision to submit the article for publication.

\section{Availability of data and materials}

Merck Sharp \& Dohme Corp., a subsidiary of Merck \& Co., Inc., Kenilworth, NJ, USA's data sharing policy, including restrictions, is available at http:// engagezone.msd.com/ds_documentation.php. Requests for access to the clinical study data can be submitted through the EngageZone site or via email to dataaccess@merck.com.

\section{Ethics approval and consent to participate}

All procedures performed in studies involving human participants were in accordance with the ethical standards of the institutional and/or national research committee and with the 1964 Helsinki Declaration and its later amendments or comparable ethical standards. Written informed consent was obtained from all individual participants included in the study. The protocol was approved by institutional review boards or ethics committees at all sites (names listed in Additional file 1).

\section{Consent for publication}

Not applicable.

\section{Competing interests}

Dr. Weinstein is an employee of Merck Sharp \& Dohme Corp., a subsidiary of Merck \& Co., Inc., Kenilworth, NJ, USA, and is a stockholder in Merck \& Co., Inc., Kenilworth, NJ, USA. Dr. Jordan served as an advisor for Merck Sharp \& Dohme Corp., Amgen, Hexal, Riemser, Helsinn, Tesaro, Kreussler, Voluntis, Pfizer, Pomme-med, Pharma Mar, Prime Oncology, OnkoUpdate, Annals of Oncology, and UpToDate. Dr. Green is an employee of Merck Sharp \& Dohme 
Corp., a subsidiary of Merck \& Co., Inc., Kenilworth, NJ, USA, and is a stockholder in Merck \& Co., Inc., Kenilworth, NJ, USA. Dr. Khanani has nothing to disclose. Dr. Beckford-Brathwaite was an employee of Merck Sharp \& Dohme Corp., a subsidiary of Merck \& Co., Inc., Kenilworth, NJ, USA. Dr. Vallejos is an employee of Merck Sharp \& Dohme Corp., a subsidiary of Merck \& Co., Inc., Kenilworth, NJ, USA, and is a stockholder in Merck \& Co., Inc., Kenilworth, NJ, USA. Dr. Pong is an employee of Merck Sharp \& Dohme Corp., a subsidiary of Merck \& Co., Inc., Kenilworth, NJ, USA, and is a stockholder in Merck \& Co., Inc., Kenilworth, NJ, USA. Dr. Noga is now an employee of Takeda Oncology. Dr. Rapoport served as an advisor for Merck Sharp \& Dohme Corp., Tesaro, and Heron Therapeutics, and acted on speakers' bureaus for Merck Sharp \& Dohme Corp., Roche, and Tesaro, and received a research grant from Tesaro.

\section{Author details}

${ }^{1}$ Merck \& Co., Inc., 2000 Galloping Hill Road, Kenilworth, NJ, USA. ${ }^{2}$ University of Heidelberg, Im Neuenheimer Feld 400, 69120 Heidelberg, Germany. ${ }^{3}$ Heywood Hospital, 242 Green Street, Gardner, MA, USA. ${ }^{4}$ Weinberg Cancer Institute, 9103 Franklin Square Drive, Baltimore, MD, USA. ${ }^{5}$ Department of Immunology, Faculty of Health Sciences, University of Pretoria, Corner Doctor Savage Road and Bophelo Road, Pretoria 0002, South Africa. ${ }^{6}$ The Medical Oncology Centre of Rosebank, 129 Oxford Road, Saxonwold, Johannesburg 2196, South Africa.

Received: 22 August 2019 Accepted: 4 August 2020

Published online: 25 September 2020

\section{References}

1. Chan VT, Yeo W. Antiemetic therapy options for chemotherapy-induced nausea and vomiting in breast cancer patients. Breast Cancer (Auckl). 2011:3:151-60

2. Mizuno M, Hiura M, Kikkawa F, et al. A prospective observational study on chemotherapy-induced nausea and vomiting (CINV) in patients with gynecologic cancer by the CINV study group of Japan. Gynecol Oncol. 2016;140:559-64

3. Ishikawa A, Ohara G, Nakazawa K, et al. Chemotherapy-induced complications in patients with lung cancer: an evaluation by pharmacists. Mol Clin Oncol. 2013;1:65-8.

4. Roila F, Molassiotis A, Herrstedt J, et al. 2016 MASCC and ESMO guideline update for the prevention of chemotherapy- and radiotherapy-induced nausea and vomiting and of nausea and vomiting in advanced cancer patients. Ann Oncol. 2016;27:v119-v33.

5. Jordan K, Jahn F, Aapro M. Recent developments in the prevention of chemotherapy-induced nausea and vomiting (CINV): a comprehensive review. Ann Oncol. 2015;26:1081-90.

6. National Comprehensive Cancer Network. NCCN Clinical Practice Guidelines in Oncology (NCCN Guidelines ${ }^{\circledR}$ ). Antiemesis. Version 2. 2017 — March 28, 2017.

7. Hesketh PJ. Defining the emetogenicity of cancer chemotherapy regimens: relevance to clinical practice. Oncologist. 1999:4:191-6.

8. Oncology Nursing Society. Emetogenic risk of chemotherapy and biotherapy agents. In: Defining the Emetogenicity of Cancer Chemotherapy Regimens: Relevance to Clinical Practice, vol. 2. 3rd ed. Pittsburgh: Oncology Nursing Society; 2018.

9. Hesketh PJ, Kris MG, Basch E, et al. Antiemetics: American Society of Clinical Oncology clinical practice guideline update. J Clin Oncol. 2017;35:3240-61.

10. Merck Sharp \& Dohme Corp. EMEND (fosaprepitant) for injection, for intravenous use. Whitehouse Station: Merck Sharp \& Dohme Corp; 2018

11. Weinstein C, Jordan K, Green SA, et al. Single-dose fosaprepitant for the prevention of chemotherapy-induced nausea and vomiting associated with moderately emetogenic chemotherapy: results of a randomized, doubleblind phase III trial. Ann Oncol. 2016;27:172-8.

12. American Society of Clinical Oncology, Kris MG, Hesketh PJ, et al. American Society of Clinical Oncology guideline for antiemetics in oncology: update 2006. J Clin Oncol. 2006:24:2932-47.

13. Basch E, Prestrud AA, Hesketh PJ, et al. Antiemetics: American Society of Clinical Oncology clinical practice guideline update. J Clin Oncol. 2011;29: 4189-98.

14. Ng TL, Hutton B, Clemons M. Chemotherapy-induced nausea and vomiting: time for more emphasis on nausea? Oncologist. 2015;20:576-83.

15. Mantel N, Haenszel W. Statistical aspects of the analysis of data from retrospective studies of disease. J Natl Cancer Inst. 1959;22:719-48.
16. Miettinen O, Nurminen M. Comparative analysis of two rates. Stat Med. 1985:4:213-26.

17. Kaplan EL, Meier P. Nonparametric estimation from incomplete observations. J Am Stat Assoc. 1958:53:457-81.

18. Dranitsaris G, Molassiotis A, Clemons M, et al. The development of a prediction tool to identify cancer patients at high risk for chemotherapyinduced nausea and vomiting. Ann Oncol. 2017;28:1260-7.

19. Weinstein C, Jordan K, Green SA, et al. Evaluation of factors contributing to the response to fosaprepitant in a heterogeneous, moderately emetogenic chemotherapy population: an exploratory analysis of a randomized phase III trial. Support Care Cancer. 2018;26:3773-80.

20. Rapoport BL, Chasen MR, Gridelli C, et al. Safety and efficacy of rolapitant for prevention of chemotherapy-induced nausea and vomiting after administration of cisplatin-based highly emetogenic chemotherapy in patients with cancer: two randomised, active-controlled, double-blind, phase 3 trials. Lancet Oncol. 2015;16:1079-89.

21. Rapoport BL, Aapro M, Chasen MR, et al. Recent developments in the clinical pharmacology of rolapitant: subanalyses in specific populations. Drug Des Devel Ther. 2017;11:2621-9.

22. Aapro MS, Schmoll HJ, Jahn F, Carides AD, Webb RT. Review of the efficacy of aprepitant for the prevention of chemotherapy-induced nausea and vomiting in a range of tumor types. Cancer Treat Rev. 2013;39:113-7.

23. Zhang XH, Hao S, Gao B, et al. A network meta-analysis for toxicity of eight chemotherapy regimens in the treatment of metastatic/advanced breast cancer. Oncotarget. 2016;7:84533-43.

24. Casamayor M, Morlock R, Maeda H, Ajani J. Targeted literature review of the global burden of gastric cancer. Ecancermedicalscience. 2018;12:883.

\section{Publisher's Note}

Springer Nature remains neutral with regard to jurisdictional claims in published maps and institutional affiliations.
Ready to submit your research? Choose BMC and benefit from:

- fast, convenient online submission

- thorough peer review by experienced researchers in your field

- rapid publication on acceptance

- support for research data, including large and complex data types

- gold Open Access which fosters wider collaboration and increased citations

- maximum visibility for your research: over $100 \mathrm{M}$ website views per year

At $\mathrm{BMC}$, research is always in progress.

Learn more biomedcentral.com/submissions 